\title{
Photocatalytic oxidation of nitrite ion over carbon nitride
}

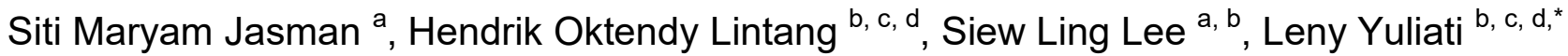 \\ a Department of Chemistry, Faculty of Science, Universiti Teknologi Malaysia, 81310 UTM Johor Bahru, Johor, Malaysia \\ ${ }^{b}$ Centre for Sustainable Nanomaterials, Ibnu Sina Institute for Scientific and Industrial Research, Universiti Teknologi Malaysia, 81310 UTM Johor \\ Bahru, Johor, Malaysia \\ Ma Chung Research Center for Photosynthetic Pigments, Universitas Ma Chung, Villa Puncak Tidar N-01, Malang 65151, East Java, Indonesia \\ ${ }^{d}$ Department of Chemistry, Faculty of Science and Technology, Universitas Ma Chung, Villa Puncak Tidar N-01, Malang 65151, East Java, \\ Indonesia \\ * Corresponding author: leny.yuliati@machung.ac.id
}

\section{Article history}

Submitted 18 January 2018

Revised 31 January 2018

Accepted 15 March 2018

Published online 30 April 2018

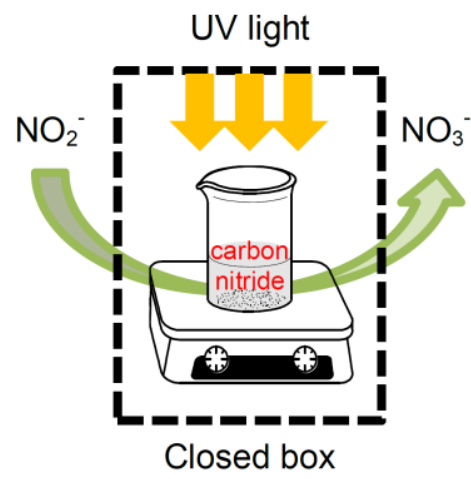

\begin{abstract}
Nitrite ion $\left(\mathrm{NO}_{2}{ }^{-}\right)$is a toxic inorganic contaminant, which is widely used in industry and agriculture as a food preservative and a fertilizing agent. One of the methods to reduce the toxicity of the $\mathrm{NO}_{2}{ }^{-}$is by oxidizing it into less hazardous compounds, such as nitrate ion $\left(\mathrm{NO}_{3}{ }^{-}\right)$. In this study, we demonstrated that a simple and green photocatalytic process can be employed to oxidize the $\mathrm{NO}_{2}{ }^{-}$to $\mathrm{NO}_{3}{ }^{-}$over a metal free-carbon nitride photocatalyst under ultraviolet (UV) light irradiation. The carbon nitride was synthesized via pyrolysis of urea precursor by a thermal polymerization process at $823 \mathrm{~K}$ for 4 hours. The prepared carbon nitride was then characterized by using X-ray diffractometer (XRD), field emission scanning electron microscope (FESEM), diffuse reflectance UV-visible (DR UV-vis), fluorescence, and Fourier transform infrared (FTIR) spectrophotometers, as well as nitrogen adsorption-desorption isotherm analyzer. All the characterization results supported the successful synthesis of the carbon nitride. The carbon nitride was then used as the photocatalyst for oxidation of $\mathrm{NO}_{2}^{-}$to $\mathrm{NO}_{3}^{-}$under UV light irradiation for $3 \mathrm{~h}$. The decrease of the $\mathrm{NO}_{2}^{-}$and the formation of the $\mathrm{NO}_{3}{ }^{-}$were analyzed by using a high performance liquid chromatography (HPLC) equipped with Hypersil Gold ${ }^{\mathrm{TM}}$ PFP column. The mobile phase used was a mixture of methanol $(\mathrm{MeOH})$ and water $\left(\mathrm{H}_{2} \mathrm{O}\right)$ with the ratio of $\mathrm{MeOH}: \mathrm{H}_{2} \mathrm{O}$ was $30: 70$. The addition of orthophosphoric acid was required to set the $\mathrm{pH}$ at 2.5. The flow rate was fixed at $0.8 \mathrm{ml} \mathrm{min}^{-1}$ and the monitored wavelength was $220 \mathrm{~nm}$. It was revealed that carbon nitride could oxidize $\mathrm{NO}_{2}^{-}$to $\mathrm{NO}_{3}^{-}$with a moderate conversion of $15 \%$. Fluorescence quenching showed that there were good interactions between the emission sites of carbon nitride and the $\mathrm{NO}_{2}^{-}$molecules. The good interactions would be one driving force for the carbon nitride to act as a good photocatalyst to oxidize the $\mathrm{NO}_{2}^{-}$to $\mathrm{NO}_{3}^{-}$. The oxidation pathway by the photogenerated species was also proposed.
\end{abstract}

Keywords: Carbon nitride, nitrite ion, oxidation, photocatalyst

() 2018 Penerbit UTM Press. All rights reserved

\section{INTRODUCTION}

Nitrite $\left(\mathrm{NO}_{2}^{-}\right)$is a common pollutant in the environment as it is largely employed as a food preservative and a fertilizing agent. This has caused the increase in the contamination of the water resource for human consumption (Wang et al., 2017). The $\mathrm{NO}_{2}^{-}$can be harmful to human health when it reacts with secondary amines and amides in the gastrointestinal tract since it may form carcinogenic $N$-nitrosamine, which can cause stomach cancer (Kodamatani et al., 2009; Santarelli et al., 2008). Other than that, $\mathrm{NO}_{2}^{-}$also can interact with blood pigments to produce methemoglobinemia or baby blue syndrome, which can cause blood disorder and breathing difficulties in human (Bagheri et al., 2017; Wang et al., 2016). In addition, the World Health Organization (WHO) has set the maximum concentration level of the $\mathrm{NO}_{2}^{-}$in drinking water to $1 \mathrm{mg} / \mathrm{L}$ (WHO, 2011). Therefore, the conversion of $\mathrm{NO}_{2}{ }^{-}$to the less hazardous compound is regarded to be very significant from the human health and environmental point of view. The development of green methods to reduce the existence of $\mathrm{NO}_{2}{ }^{-}$in drinking water remains an important challenge to be achieved.
Among many different approaches for removal of pollutant from water, photocatalysis and electrochemical oxidation are considered as the most efficient methods for degradation of pollutants in water (Quiroz et al., 2011). However, the electrochemical method suffers from the high cost of electrodes, the demand for energy, and formation of by-product (Woisetschläger et al., 2013). In contrast, photocatalytic degradation of organic pollutant has attracted a great interest due to the low cost of available photocatalysts, the possibility to utilize renewable light energy, and the ability of the photocatalyst to catalyze the total oxidation of organic pollutants, which overall result in the environmental protection. It has been found that the organic matter and contaminations in water can be completely mineralized by light irradiation using UV light, visible light or sunlight in the presence of suitable semiconductor photocatalyst. While the oxidation of $\mathrm{NO}_{2}^{-}$to $\mathrm{NO}_{3}^{-}$can be carried out by oxygen in water at room temperature, the oxidation rate of the oxidation $\mathrm{NO}_{2}^{-}$is very slow. In the presence of light and semiconductor acting as a photocatalyst, the oxidation of the $\mathrm{NO}_{2}^{-}$can be speeded up. In 
addition, by using this method, $\mathrm{NO}_{2}{ }^{-}$can be converted to $\mathrm{NO}_{3}{ }^{-}$, which is a less hazardous compound (Navío et al., 1998).

In this work, carbon nitride was used as a metal-free photocatalyst for oxidation of $\mathrm{NO}_{2}^{-}$to $\mathrm{NO}_{3}^{-}$. Carbon nitride is a polymeric semiconductor having a similar structure to graphene, but different properties. Owing to its unique physical and chemical properties, carbon nitride has been widely used as an active photocatalyst for degradation and oxidation of organic pollutants (Lee et al., 2012; Yan et al., 2009) as well as water splitting reactions (Wang et al., 2009; Zhang et al., 2012). Carbon nitride and its composites have been also investigated as a potential fluorescence sensor for several nitrogencontaining compounds, such as $\mathrm{N}$-Nitrosopyrrolidone (Sam et al., 2012), $\mathrm{NO}_{3}^{-}$(Alim et al., 2015; Jasman et al., 2017a), and $\mathrm{NO}_{2}$ (Jasman et al., 2017b). Such molecular interactions on the carbon nitride might lead the carbon nitride to act as a good photocatalyst for the nitrogen-containing compound. This study highlighted the first use of carbon nitride to photocatalytically oxidize the $\mathrm{NO}_{2}{ }^{-}$to $\mathrm{NO}_{3}{ }^{-}$. The characterizations of the prepared carbon nitride and the fluorescence quenching in the presence of $\mathrm{NO}_{2}^{-}$were discussed and the pathway of photogenerated hole and electron was proposed.

\section{EXPERIMENTAL}

\section{Materials}

All chemicals used throughout this study were purchased and used without any treatments. The carbon nitride was synthesized by using urea $\left(\mathrm{CO}\left(\mathrm{NH}_{2}\right)_{2}\right)$ as the precursor, which was purchased from SigmaAldrich (99\%). The sodium nitrite $\left(\mathrm{NaNO}_{2}\right)$ used as the source of $\mathrm{NO}_{2}{ }^{-}$was supplied from Sigma-Aldrich $(97 \%)$. Diammonium oxalate monohydrate $\left(\left(\mathrm{NH}_{4}\right)_{2} \mathrm{C}_{2} \mathrm{O}_{4} \cdot \mathrm{H}_{2} \mathrm{O}\right)$ purchased from Merck $(99 \%)$ was used as a hole scavenger used in the photocatalytic oxidation process.

\section{Synthesis of Carbon Nitride}

The carbon nitride was synthesized in a similar way to the reported synthesis of bulk carbon nitride (Lee et al., 2012). A certain amount of urea was calcined at $823 \mathrm{~K}$ for 4 hours with the heating rate of $2.2 \mathrm{~K} \mathrm{~min}^{-1}$ in a ceramic crucible with a closed cover via thermal polymerization technique. The resultant yellow colored powder was ground and collected as the carbon nitride sample.

\section{Characterizations of Carbon Nitride}

XRD pattern of the carbon nitride was obtained from an X-ray diffractometer (Bruker D8 Advance), using $\mathrm{Cu} \mathrm{K}_{\alpha}$ irradiation with $\lambda$ of $1.5406 \AA$ and a scan rate of $0.05^{\circ} \mathrm{s}^{-1}$. The morphology of carbon nitride was observed by using FESEM on a JEOL JSM-6701F microscope operating at $15 \mathrm{kV}$, recorded at a magnification of 10,000 times. The carbon nitride sample was coated with $\mathrm{Pt}$ prior to the measurement. FTIR spectrum was recorded at room temperature by using a Nicolet iS50 spectrophotometer by mixing the carbon nitride sample with $\mathrm{KBr}$ to form a pellet. Nitrogen adsorption-desorption isotherm was measured at $77 \mathrm{~K}$ on a Quantachrome NOVAtouch LX4. Prior to the measurement, the carbon nitride was degassed for 2 hours at $393 \mathrm{~K}$. The absorption spectrum of carbon nitride at UV and visible region was measured by a Shimadzu UV-2600 in the range of $250-800 \mathrm{~nm}$, where barium sulfate was used as the reference. The excitation and emission spectra of the carbon nitride were obtained by measurements at room temperature on a JASCO FP-8500 fluorescence spectrophotometer.

\section{Photocatalytic Activity Test}

Photocatalytic activity of carbon nitride was evaluated for the oxidation of $\mathrm{NO}_{2}^{-}$under UV light irradiation. The stock solution of $\mathrm{NO}_{2}^{-}(8 \mathrm{ppm})$ was prepared by diluting $8 \mathrm{mg}$ of sodium nitrite in $1 \mathrm{~L}$ distilled water. Before the reaction, $0.05 \mathrm{~g}$ of carbon nitride was dispersed in $50 \mathrm{~mL} \mathrm{NO}_{2}^{-}$solution and stirred under dark conditions for $1 \mathrm{~h}$ to establish the adsorption-desorption equilibrium. Diammonium oxalate monohydrate $(0.002 \mathrm{~g})$ was introduced into the mixture as the hole scavenger and the mixture was then irradiated for
$3 \mathrm{~h}$ by a $200 \mathrm{~W}$ Xe-Hg lamp equipped with an infrared cut-off filter. The light intensity was measured to be $6 \mathrm{~mW} \mathrm{~cm}^{-2}$. The mixture was then filtered through a membrane filter $(0.22 \mu \mathrm{M})$. The $\mathrm{NO}_{2}{ }^{-}$and $\mathrm{NO}_{3}{ }^{-}$ peaks were analyzed by using a high performance liquid chromatography (HPLC) equipped with Hypersil Gold ${ }^{\mathrm{TM}}$ PFP column. The mobile phase used was $\mathrm{MeOH}: \mathrm{H}_{2} \mathrm{O}$ (30:70) with the addition of orthophosphoric acid to set the $\mathrm{pH}$ at 2.5. This condition was essential to get good separation between the peaks of $\mathrm{NO}_{3}{ }^{-}$and $\mathrm{NO}_{2}^{-}$. The flow rate was fixed at $0.8 \mathrm{ml} \mathrm{min}^{-1}$ and the monitored wavelength was $220 \mathrm{~nm}$.

\section{RESULTS AND DISCUSSION}

\section{Characterizations}

Fig. 1 shows the XRD pattern of the prepared carbon nitride. From the diffraction pattern, two obvious peaks were observed at $2 \theta$ of 13.10 and $27.30^{\circ}$. The broad peak at $2 \theta$ of $13.10^{\circ}$ corresponded to (100) plane with $d$-spacing of $0.64 \mathrm{~nm}$, showing the in-planar repeating units and the distance between the nitride pores. On the other hand, the stronger diffraction peak at $2 \theta$ of $27.30^{\circ}$ could be assigned as the (002) plane with $d$-spacing of $0.35 \mathrm{~nm}$, which was described as the distance between the layers of the graphitic material. These diffraction peaks are in good agreement with previous reports on graphitic carbon nitride prepared by urea precursor (Alim et al., 2015; Lee et al., 2012; Liu et al., 2011; Jasman et al., 2017a; Jasman et al., 2017b; Zhang et al., 2012). Fig. 1 also displays the FESEM image of the carbon nitride. The FESEM image showed that the carbon nitride composed of layers with uneven tremella-like structure.

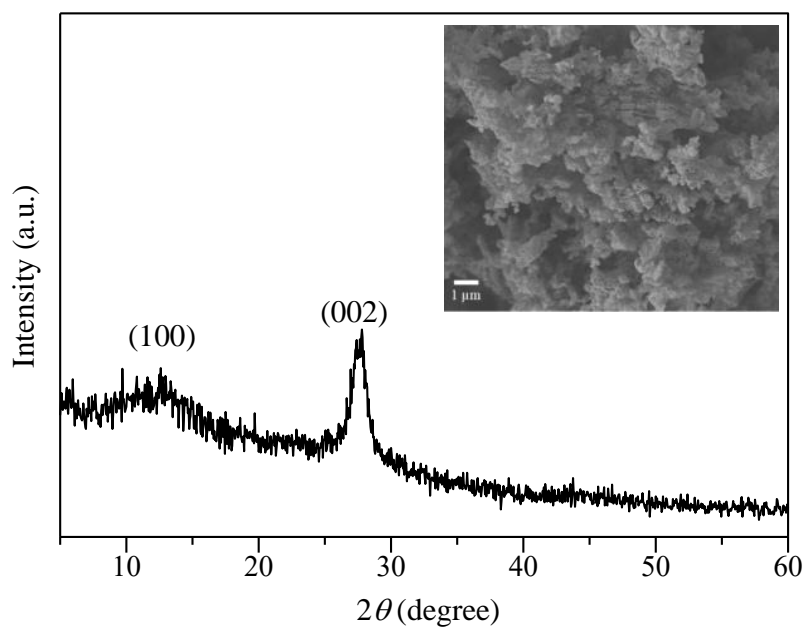

Fig. 1 XRD pattern and FESEM image (inset) of carbon nitride.

As observed in Fig. 2, carbon nitride has three important absorption peaks, which were observed at around 277, 315 and 369 $\mathrm{nm}$, in good agreement with the reported literature (Alim et al., 2015, Jasman et al., 2017a; Jasman et al., 2017b). The absorption peaks at 277 and $369 \mathrm{~nm}$ were more likely attributed from the $\pi-\pi^{*}$ and $n-\pi^{*}$ electronic transitions of conjugated aromatic $s$-triazine ring system, while the absorption peak at $315 \mathrm{~nm}$ could be assigned to the presence of $\mathrm{C}=\mathrm{O}$ groups due to the less condensation of urea precursor during the polymerization process (Liu et al., 2011).

The bandgap energy $\left(E_{g}\right)$ of the carbon nitride could be calculated by using the Tauc plot. The Tauc equation was plotted to obtain a graph of $(\alpha \mathrm{h} v)^{n}$ versus photon energy (hv), where $\alpha$ is absorption coefficient, and $n$ was fixed to 0.5 for the indirect allowed transition. The $\alpha$ value could be obtained from the DR UV-vis spectrum since the Kubelka-Munk function is directly proportional to the $\alpha$. The bandgap energy value was obtained by extrapolating the linear part at the energy axis. As shown in the inset of Fig. 2, the bandgap energy of the carbon nitride could be estimated to be $c a .2 .8 \mathrm{eV}$, close to the reported bandgap energy value (Zhang et al., 2012). 


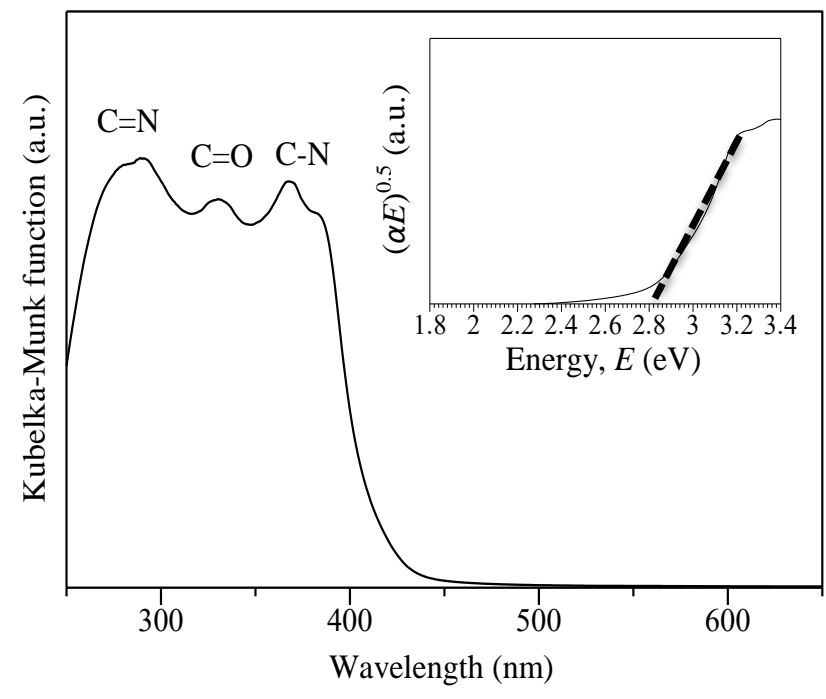

Fig. 2 DR UV-vis spectrum and Tauc plot (inset) of carbon nitride.

Fig. 3 shows the excitation and emission spectra of carbon nitride measured by fluorescence spectrophotometer. Similar to the optical properties of carbon nitride shown in Fig. 2, the excitation peaks were also observed at 277, 315, and $369 \mathrm{~nm}$. The excitations at 277 and 369 $\mathrm{nm}$ were related to the $\mathrm{C}=\mathrm{N}\left(\pi-\pi^{*}\right)$ and $\mathrm{C}-\mathrm{N}\left(n-\pi^{*}\right)$ electronic transitions in the conjugated polymer units and covalent nitrogen in the $s$-triazine ring, while the excitation at $315 \mathrm{~nm}$ was due to the presence of $\mathrm{C}=\mathrm{O}$ moiety (Alim et al., 2015, Jasman et al., 2017a; Jasman et al., 2017b; Zhang et al., 2012). All three excitation peaks exhibited one emission peak at a wavelength of $c a .450 \mathrm{~nm}$. The intensity of the emission peak excited at different wavelengths was found to be slightly different from each other.

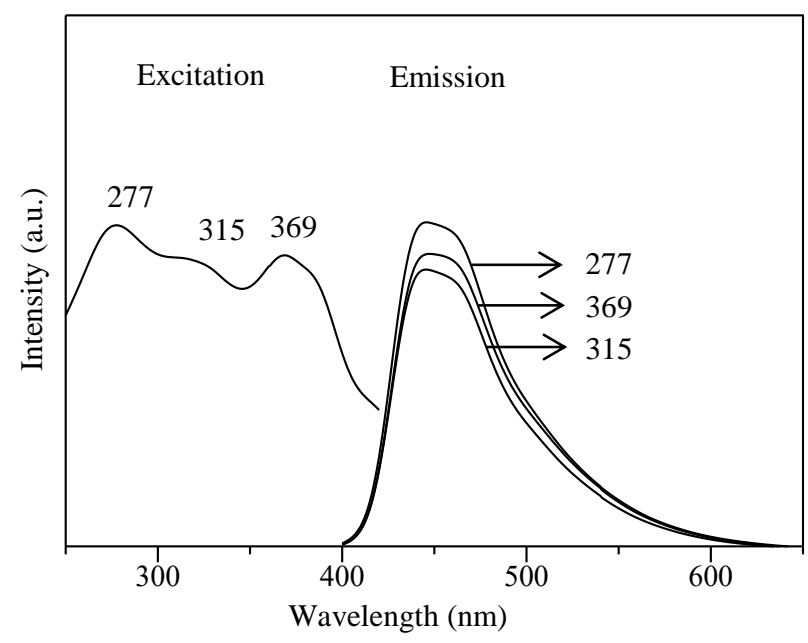

Fig. 3 Excitation and emission spectra of carbon nitride.

As shown in Fig. 4, the carbon nitride showed vibration bands in the region of $3300-3400 \mathrm{~cm}^{-1}$, which referred to the primary and secondary amines. These bands could be also the result of overlapping bands from the incomplete condensation process of $v(\mathrm{O}-\mathrm{H})$ group. As for the stretching modes of $v(\mathrm{C}=\mathrm{O})$ and $v(\mathrm{C}-\mathrm{N})$ heterocycles, they were observed around $1200-1700 \mathrm{~cm}^{-1}$. The stretching band at 809 $\mathrm{cm}^{-1}$ showed the presence of heterocyclic tri-s-azine ring $\left(\mathrm{C}_{6} \mathrm{H}_{7}\right)$, which is the characteristic of the carbon nitride. These observed vibration bands agreed well with the reported ones observed on the carbon nitride prepared by urea precursor (Alim et al., 2015; Liu et al., 2011; Jasman et al., 2017a; Jasman et al., 2017b), suggesting the successful formation of carbon nitride.

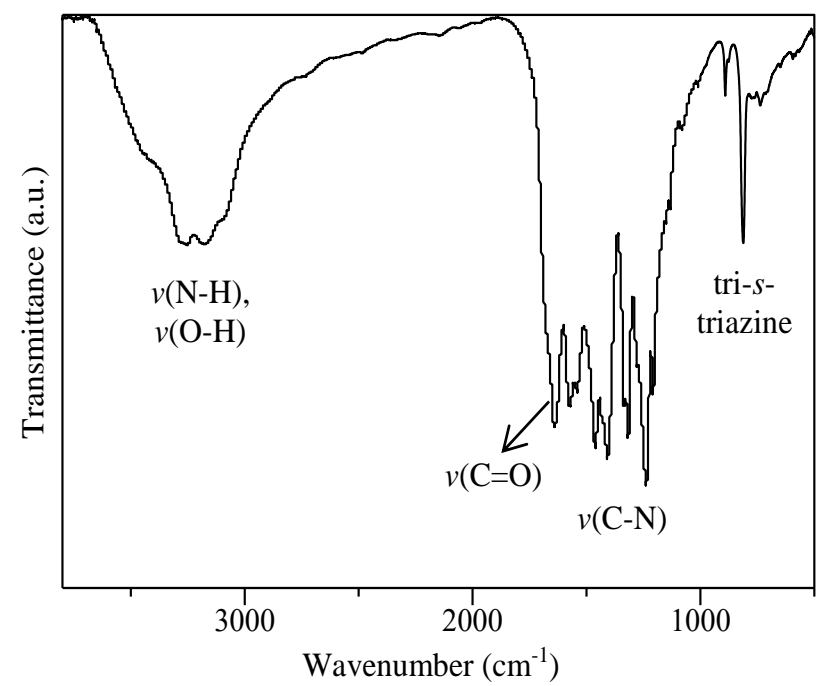

Fig. 4 FTIR spectrum of carbon nitride.

Fig. 5 depicts the nitrogen adsorption-desorption isotherm of the carbon nitride. The isotherm showed that the carbon nitride has the characteristic of type IV isotherm with a distinct $\mathrm{H} 3$ hysteresis loop at the relative pressure $\left(P / P_{o}\right)$ with the range of $0.5-1.0$. The isotherm suggested that the carbon nitride has mesoporosity. The BarrettJoyner-Halenda $(\mathrm{BJH})$ pore-size distribution is shown as the inset of Fig. 5. Based on the BJH results, the carbon nitride was shown to have a porosity which size was in the range of $2-50 \mathrm{~nm}$, where the largest distribution of porosity has a pore size of $c a .3 .8 \mathrm{~nm}$. It has been reported that the formation of mesoporosity in carbon nitride prepared by urea precursor was related to the released gas bubbles produced from the pyrolysis of urea during the polymerization treatment (Zhang et al., 2012). The Brunauer-Emmet-Teller (BET) specific surface area of the carbon nitride was determined to be $90 \mathrm{~m}^{2} \mathrm{~g}^{-1}$. The high surface area of the carbon nitride would be beneficial as it would provide a large number of exposed active sites to the reactant and thus, expected to have high photocatalytic activity.

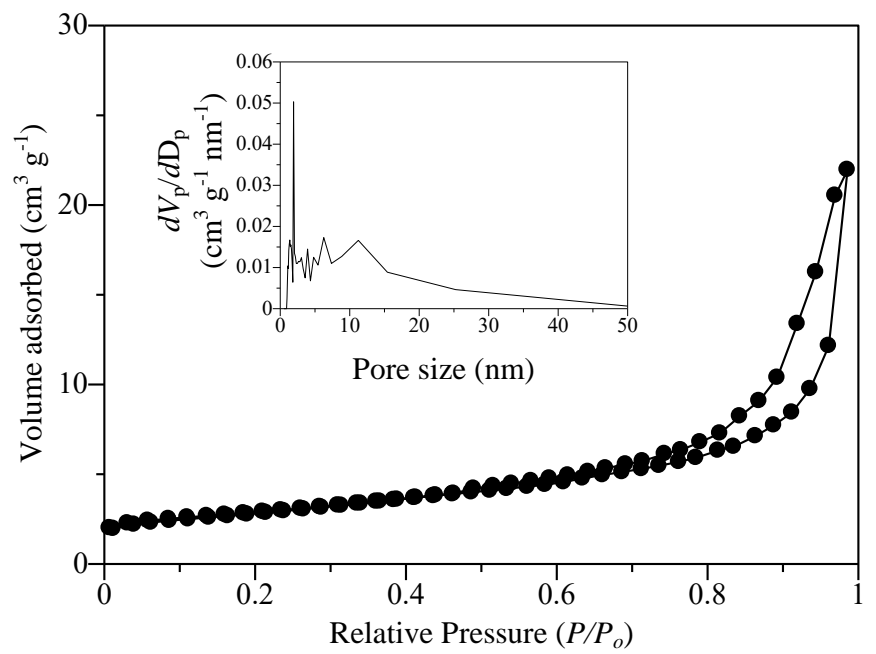

Fig. 5 Nitrogen adsorption-desorption isotherm and BJH pore size distribution (inset) of carbon nitride.

\section{Interactions with $\mathrm{NO}_{2}^{-}$}

Fluorescence quenching study has been carried out in order to investigate the interaction between the emission sites of the carbon nitride and the $\mathrm{NO}_{2}^{-}$molecules. The fluorescence quenching can be measured quantitatively using the Stern-Volmer equation as shown in Eq. (1) below.

$$
I_{0} / I=K s v[Q]+1
$$


The $I$ and $I_{0}$ show the fluorescence emission intensity with and without the quencher, respectively, [Q] is the quencher concentration, and $K s v$ represents the Stern-Volmer constant. In this study, the quencher was $\mathrm{NO}_{2}^{-}$and the amount of $\mathrm{NO}_{2}^{-}$was investigated in the range of 5-40 mol.

As displayed in Fig. 6, the emission intensity of carbon nitride was quenched with the addition of $\mathrm{NO}_{2}^{-}$. It was obvious that regardless the excitation wavelength, all the emission sites were quenched by the $\mathrm{NO}_{2}^{-}$. The higher amount of the $\mathrm{NO}_{2}^{-}$led to the more quenched emission intensity, suggesting that there were interactions between the added $\mathrm{NO}_{2}{ }^{-}$and all the emission sites.

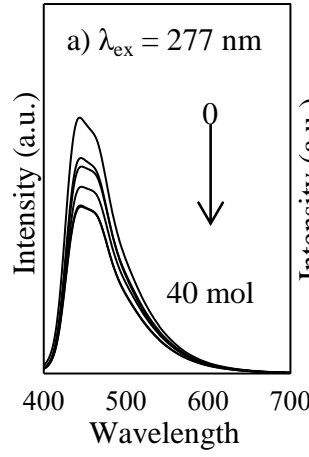

$(\mathrm{nm})$

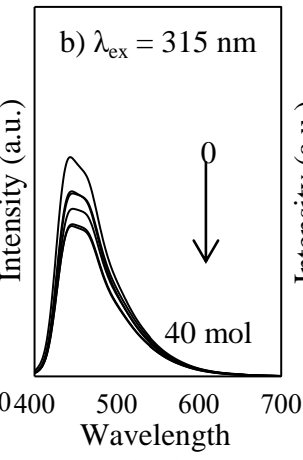

(nm)

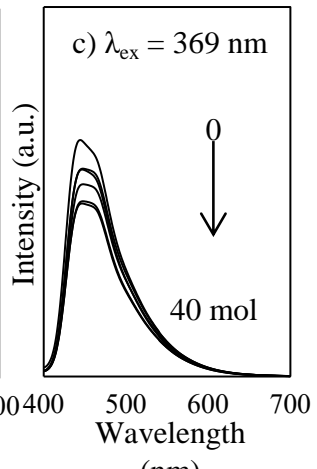

(nm)
Fig. 6 Interactions between the added $\mathrm{NO}_{2}^{-}$and emission sites when excited at (a) 277, (b) 315, and (c) $369 \mathrm{~nm}$.

The quenching efficiency of the carbon nitride towards the $\mathrm{NO}_{2}$ can be determined from the $K s v$ values obtained from the slopes of Stern-Volmer plots according to the Eq. (1) and shown in Fig. 7. The linear lines observed from the Stern-Volmer plots suggested that the decrease of the emission intensity was a function of $\mathrm{NO}_{2}$ concentration. As aforementioned, carbon nitride has three excitation wavelengths at 277,315 and $369 \mathrm{~nm}$. The $K s v$ values of carbon nitride monitored at 277, 315 and $369 \mathrm{~nm}$, which corresponded to $\mathrm{C}=\mathrm{N}$, $\mathrm{C}=\mathrm{O}$, and $\mathrm{C}-\mathrm{N}$ groups, were determined to be $6.9 \times 10^{-3}, 6.37 \times 10^{-3}$, and $5.39 \times 10^{-3} \mathrm{~mol}^{-1}$, respectively. Based on this result, the $\mathrm{C}=\mathrm{N}$ sites were confirmed to give the strongest interactions with the $\mathrm{NO}_{2}^{-}$, followed by $\mathrm{C}=\mathrm{O}$ and $\mathrm{C}-\mathrm{N}$ sites.

\section{Photocatalytic Activity}

The photocatalytic activity of the carbon nitride was evaluated for oxidation of $\mathrm{NO}_{2}^{-}$under UV light irradiation for $3 \mathrm{~h}$. Prior to the reaction, the mixture of $\mathrm{NO}_{2}^{-}$aqueous solution and the carbon nitride was stirred in the dark condition for $1 \mathrm{~h}$ to reach the adsorption equilibrium. The adsorption test for $4 \mathrm{~h}$ revealed that no formation of $\mathrm{NO}_{3}{ }^{-}$was observed, suggesting that the oxidation of $\mathrm{NO}_{2}{ }^{-}$to $\mathrm{NO}_{3}{ }^{-}$ could not occur without the UV light.

In this study, the photocatalytic reaction of $\mathrm{NO}_{2}^{-}$in aqueous solution was examined in the absence and presence of diammonium oxalate monohydrate as the hole scavenger under UV light irradiation. Unfortunately, no conversion of $\mathrm{NO}_{2}^{-}$to $\mathrm{NO}_{3}{ }^{-}$could be observed when the reaction was carried out without the presence of the hole scavenger. In contrast, in the presence of diammonium oxalate monohydrate, the $\mathrm{NO}_{2}{ }^{-}$could be oxidized to the $\mathrm{NO}_{3}{ }^{-}$. As depicted in Fig. 8, only one $\mathrm{NO}_{2}^{-}$peak was observed at the retention time of $c a .5$ min prior to the photocatalytic reaction. However, after the reaction, two peaks could be detected at the retention time of $c a .3$ and $5 \mathrm{~min}$ due to the presence of $\mathrm{NO}_{3}^{-}$and $\mathrm{NO}_{2}^{-}$, respectively. The good separation of these peaks suggested that the current method could be employed. The percentage oxidation of $\mathrm{NO}_{2}^{-}$was determined to be $15 \%$, which was calculated from Eq. (2) below.

Percentage oxidation of $\mathrm{NO}_{2}^{-}(\%)=\left(A_{0}-A_{t}\right) / A_{0} \times 100 \%$ where $A_{0}$ is the initial amount of $\mathrm{NO}_{2}^{-}$in the solution after adsorption under the dark condition, while $A_{t}$ is the amount of $\mathrm{NO}_{2}^{-}$in the solution after 3 h-reaction.

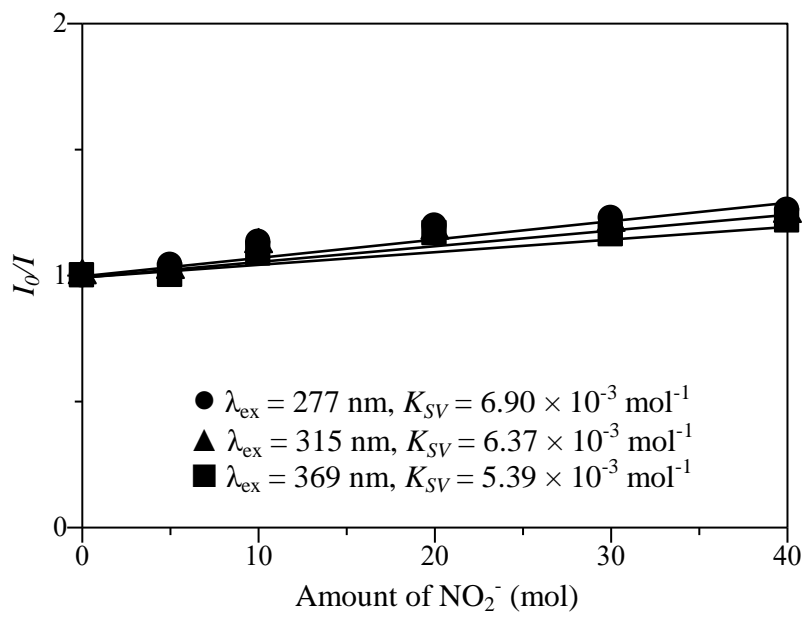

Fig. 7 Stern-Volmer plots of carbon nitride where the added $\mathrm{NO}_{2}$ amount was in the range of 5 to $40 \mathrm{~mol}$.

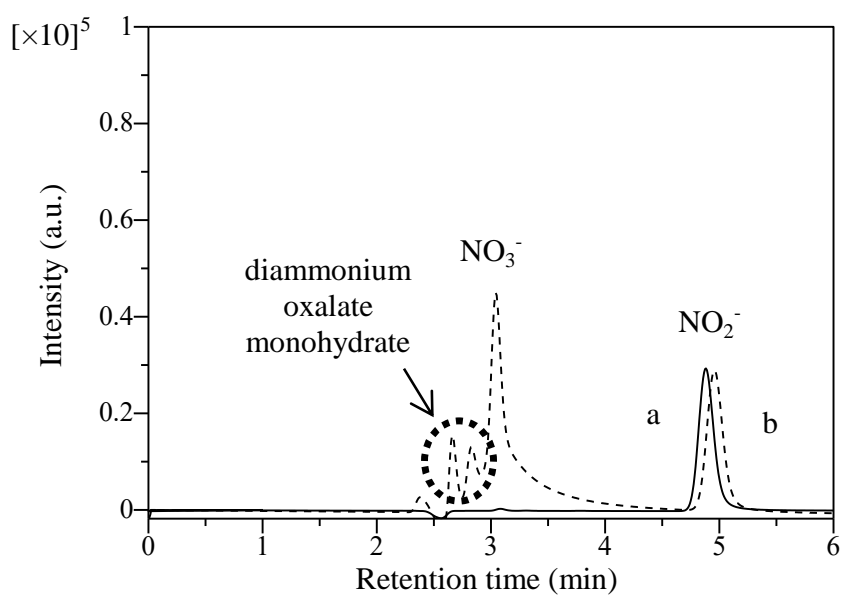

Fig. 8 HPLC chromatograms before (full line) and after reaction (dash line) for $3 \mathrm{~h}$ over the carbon nitride photocatalyst in the presence of diammonium oxalate monohydrate as the hole scavenger.

The mechanism for oxidation of $\mathrm{NO}_{2}^{-}$to $\mathrm{NO}_{3}^{-}$is proposed in Fig. 9. When the carbon nitride was irradiated by UV light, the electronhole pairs would be created on the surface of carbon nitride. Electrons would be generated at the conduction band $(\mathrm{CB})$, while holes would be generated at the valence bands (VB) of the carbon nitride. Since the oxidation reaction only occurred in the presence of hole scavenger, the holes shall be consumed to proceed the reaction. In other words, it could be suggested that the holes would not act as the active sites to oxidize the $\mathrm{NO}_{2}^{-}$. Therefore, the possible pathway to oxidize the $\mathrm{NO}_{2}^{-}$would be initiated by the photogenerated electrons. The electrons could react with oxygen to form superoxide radicals that able to oxidize the $\mathrm{NO}_{2}^{-}$. In addition, the two-electron reduction of superoxide radicals could create hydroxyl radicals (Nosaka \& Nosaka, 2012), which could further oxidize the $\mathrm{NO}_{2}^{-}$. Moreover, it has been reported that in the presence of hydrogen peroxide, the $\mathrm{NO}_{2}^{-}$could be easily converted to the $\mathrm{NO}_{3}{ }^{-}$(Kominami et al., 2014).

\section{CONCLUSION}

Carbon nitride was successfully prepared by thermal polymerization of urea as supported by various characterizations of XRD, FESEM, DR UV-vis, fluorescence, and FTIR spectroscopies, 
and nitrogen adsorption-desorption analyzer. It was demonstrated by fluorescence quenching study that the carbon nitride showed good interactions with the $\mathrm{NO}_{2}^{-}$, which led to the good activity for photocatalytic oxidation of $\mathrm{NO}_{2}^{-}$to $\mathrm{NO}_{3}^{-}$. Under UV light irradiation for $3 \mathrm{~h}$, carbon nitride exhibited photocatalytic activity with percentage degradation of $\mathrm{NO}_{2}^{-}$to $\mathrm{NO}_{3}^{-}$was $15 \%$. Since the reaction only occurred in the presence of the hole scavenger, it was proposed that the photogenerated electrons would play important roles as the active species. The electrons could react with oxygen to form superoxide radicals, which further reduced to hydrogen peroxide and hydroxyl radicals, which would oxidize $\mathrm{NO}_{2}{ }^{-}$to $\mathrm{NO}_{3}{ }^{-}$.

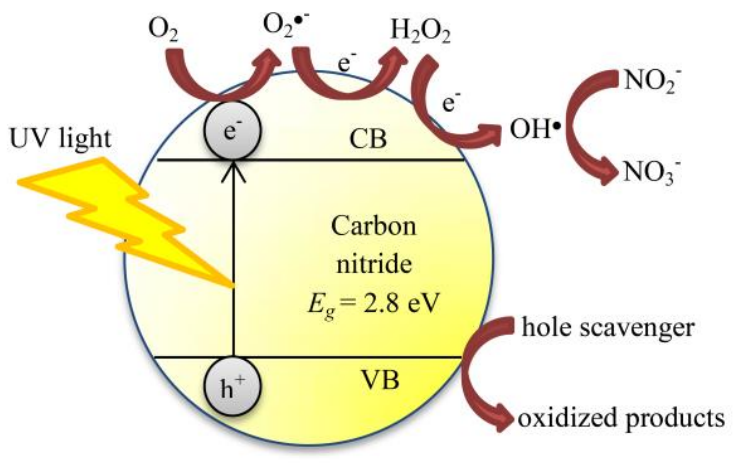

Fig. 9 Proposed mechanism of photocatalytic oxidation of $\mathrm{NO}_{2}^{-}$over carbon nitride

\section{ACKNOWLEDGEMENTS}

This work was financially supported by the Ministry of Higher Education (MOHE, Malaysia) and the Universiti Teknologi Malaysia (UTM, Malaysia) through the Research University Grant (Tier-1, cost center codes: Q.J130000.2526.10H74 and Q.J130000.2526.13H52). S.M.J also acknowledges financial support from MyBrain15 Scholarship.

\section{REFERENCES}

Alim, N. S., Lintang, H. O., Yuliati, L. 2015. Fabricated metal-free carbon nitride characterizations for fluorescence chemical sensor of nitrate ions. $J$. Teknol. 76, 13, 1-6.

Bagheri, H., Hajian, A., Rezaei, M., Shirzadmehr, A. 2017. Composite of $\mathrm{Cu}$ metal nanoparticles-multiwall carbon nanotubes-reduced graphene oxide as a novel and high performance platform of the electrochemical sensor for simultaneous determination of nitrate and nitrite. J. Hazard. Mater. 324 $762-772$.

Jasman, S. M., Lintang, H. O., Yuliati, L. 2017a. Enhanced detection of nitrite ions over copper acetylacetonate/polymeric carbon nitride composites. Macromol. Symp. 371, 84-93.
Jasman, S. M., Lintang, H. O., Lee, S. L., Yuliati, L. 2017b. Copper modified carbon nitride as fluorescence sensor for nitrate ions. Mal. J. Anal. Sci. 21, 6 , 1316-1326.

Kodamatani, H., Yamazaki, S., Saito, K., Amponsaa-Karikari, A., Kishikawa, N., Kuroda, N., Tomiyasu, T., Komatsu, Y. 2009. Highly sensitive method for determination of $N$-nitrosamines using high-performance liquid chromatography with online UV irradiation and luminol chemiluminescence detection. J. Chromatography A. 1216, 1, 92-98.

Kominami, H., Kitsui, K., Ishiyama, Y., Hashimoto, K. 2014. Simultaneous removal of nitrite and ammonia as dinitrogen in aqueous suspensions of a titanium(IV) oxide photocatalyst under reagent-free and metal-free conditions at room temperature. RSC Adv. 4, 51576-51579.

Lee, S. C., Lintang, H. O., Yuliati, L. 2012. A urea precursor to synthesize carbon nitride with mesoporosity for enhanced activity in the photocatalytic removal of phenol. Chem. Asian J. 7, 9, 2139-2144.

Liu, J., Zhang, T., Wang, Z., Dawson, G., Chen, W. 2011. Simple pyrolysis of urea into graphitic carbon nitride with recyclable adsorption and photocatalytic activity. J. Mater. Chem. 21, 38, 14398-14401.

Navío, J. A., Colón, G., Trillas, M., Peral, J., Domènech, X., Testa, J. J., Padrón, J., Rodríguez, D. Litter, M. I. 1998. Heterogeneous photocatalytic reaction of nitrite oxidation and $\mathrm{Cr}(\mathrm{VI})$ reduction on iron-doped titania prepared by the wet impregnation method. Appl. Catal. B. Environ. 16, 2, 187-196.

Nosaka, Y., Nosaka, A. Y. 2012. Identification and roles of the active species generated on various photocatalysts. Photocatalysis and Water Purification From Fundamentals to Recent Applications. Ed. Pichat, P., ISBN: 978-3527-64542-8, Wiley-VCH Verlag GmbH \& Co. KGaA.

Sam, M. S., Lintang, H. O., Sanagi, M. M., Lee, S. L., Yuliati, L. 2014. Mesoporous carbon nitride for adsorption and fluorescence sensor of $\mathrm{N}$ nitrosopyrrolidine. Spectrochim. Acta, Part A. 124, 357-364.

Santarelli, R. L., Pierre, F., Corpet, D. E. 2008. Processed meat and colorectal cancer: a review of epidemiologic and experimental evidence. Nutr. Cancer. $60,2,131-144$

Quiroz, M. A., Bandala, E. R., Martínez-Huitle, C. A. 2011. Advanced oxidation process (AOPs) for removal of pesticides from aqueous media. Pesticides-Formulations, Effects, Fate. Ed. Stoytcheva, M. ISBN: 978-953307-532-7, InTech.

Wang, X., Maeda, K., Thomas, A., Takanabe, K., Xin, G., Carlsson, J. M., Domen, K., Antonietti, M. 2009. A metal-free polymeric photocatalyst for hydrogen production from water under visible light. Nature Mater. 8, 76-80.

Wang, S., Lin, K., Chen, N., Yuan, D., Ma, J. 2016. Automated determination of nitrate plus nitrite in aqueous samples with flow injection analysis using vanadium (III) chloride as reductant. Talanta. 146, 744-748.

Wang, Q-H., Yu, L-J., Liu, Y., Lin, L., Lu, R., Zhu, J., He, L., Lu, Z-L. 2017. Methods for the detection and determination of nitrate and nitrite: A review. Talanta. 165, 709-720.

WHO, 2011. Nitrate and nitrite in drinking water. World Organization Health http://www.who.int/water_sanitation_health/dwq/chemicals/nitratenitrite2nd add.pdf (Accessed September 2017).

Woisetschläger, D., Humpl, B., Koncar, M., Siebenhofer, M. 2013. Electrochemical oxidation of wastewater - opportunities and drawbacks. Water Sci. Technol. 68, 5, 1173-1179.

Yan, S. C., Li, Z. S., Zou, Z. G. 2009. Photodegradation performance of g$\mathrm{C}_{3} \mathrm{~N}_{4}$ fabricated by directly heating melamine. Langmuir. 25, 17, $10397-$ 10401.

Zhang, Y., Liu, J., Wu, G. Chen, W. 2012. Porous graphitic carbon nitride synthesized via direct polymerization of urea for efficient sunlight-driven photocatalytic hydrogen production. Nanoscale. 4, 17, 5300-5303. 